\title{
Intraluminal Stomach Injury after Blunt Trauma
}

\author{
Dong Hun Kim1, Ye Rim Chang', Jung-Ho Yun² \\ 'Department of Trauma Surgery, Trauma Center, Dankook University Hospital, Cheonan, Republic of Korea \\ ${ }^{2}$ Department of Neurosurgery, Trauma Center, Dankook University Hospital, Cheonan, Republic of Korea
}

Isolated gastric injury caused by blunt abdominal trauma is rare, and partial thickness injury of the stomach could result in delayed presentation and diagnosis. A 51-year-old male underwent an emergency craniotomy for traumatic brain injury after a traffic accident. On the operative day, massive hematochezia was presented with unstable hemodynamics, and emergency endoscopy of the upper gastrointestinal tract revealed multiple mucosal lacerations on cardia. Finally, the patient was conservatively treated with a proton pump inhibitor and transfusions.

(Trauma Image Proced 2018(1):14-16)

Key Words: Stomach; Blunt injury; Intraluminal; Hemorrhage

\section{CASE}

A 51-year-old male was admitted to the emergency room after a traffic accident. He was a carrier of hepatitis B and had liver cirrhosis of Child Pugh classification A. Upon arrival, he was stupor with multiple laceration of the scalp and face and a belt sign on the abdomen. Physical examination revealed no peritoneal irritation signs or abdominal distension. Initial computed tomography (CT) of the abdomen revealed no definite intraabdominal organ injury, except for stomach distension with the presence of intraluminal fluid (Fig. 1.). He underwent an emergency craniotomy for traumatic epidural hematoma with stable hemodynamics. His injury severity score was 38. During intensive care, massive hematochezia was presented with hypotension, and a hemoglobin level of $6.7 \mathrm{~g} / \mathrm{dL}$ was observed at $11 \mathrm{~h}$ after the operation. In addition, esophagogastroduodenal endo- scopy revealed multiple mucosal lacerations on cardia, with active bleeding and no varices (Fig. 2.). Because his hemodynamics were stabilized with response to massive transfusion (red blood cell, 16 units; fresh frozen plasma, 13 units; platelet, 16 units), he was conservatively treated with a proton pump inhibitor, antithrombin III, and tranexamic acid, and finally progressed to full recovery.

\section{DISCUSSION}

Because the stomach is a mobile intraperitoneal organ secured in a relatively protected position, higher forces are required to injure the stomach (1). Gastric injury is classified as grade $\mathrm{I}-\mathrm{V}$ according to the Gastric Organ Injury Scale, and grade I injury represents contusion, hematoma, or partial thickness laceration (2). As grade I gastric injuries are the most abundant $(>60 \%)$, partial

Received: April 18, 2018 Revised: May 14, 2018 Accepted: May 14, 2018

Correspondence to: Dong Hun Kim, Department of Trauma Surgery, Trauma Center, Dankook University Hospital, 201 Manghyang-ro, Dongnam-gu, Cheonan 31116, Republic of Korea

Tel: 82-41-550-7661, Fax: 82-41-550-0039, E-mail: saint7331@gmail.com

Copyright (c) 2018 Korean Association for Research, Procedures and Education on Trauma. All rights reserved.

@This is an open-access article distributed under the terms of the Creative Commons Attribution Non-Commercial License (http://creativecommons.org/ licenses/by-nc/4.0) which permits unrestricted noncommercial use, distribution, and reproduction in any medium, provided the original work is properly cited 

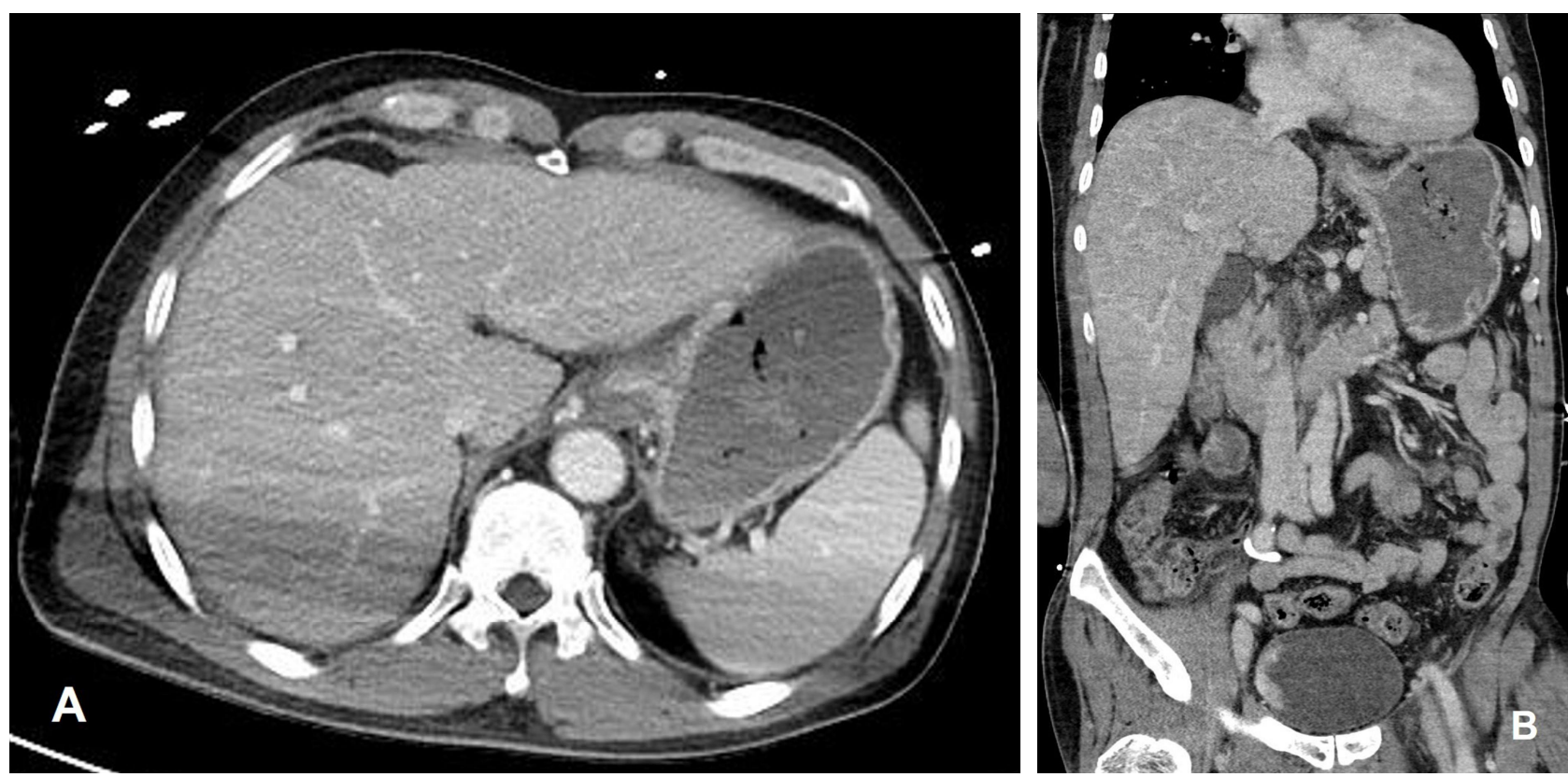

Fig. 1. Abdominal computed tomography revealed a distended stomach with nonspecific fluid and no definite abdominal organ injury with contrast extravasation. (A) Axial view, (B) Coronal view
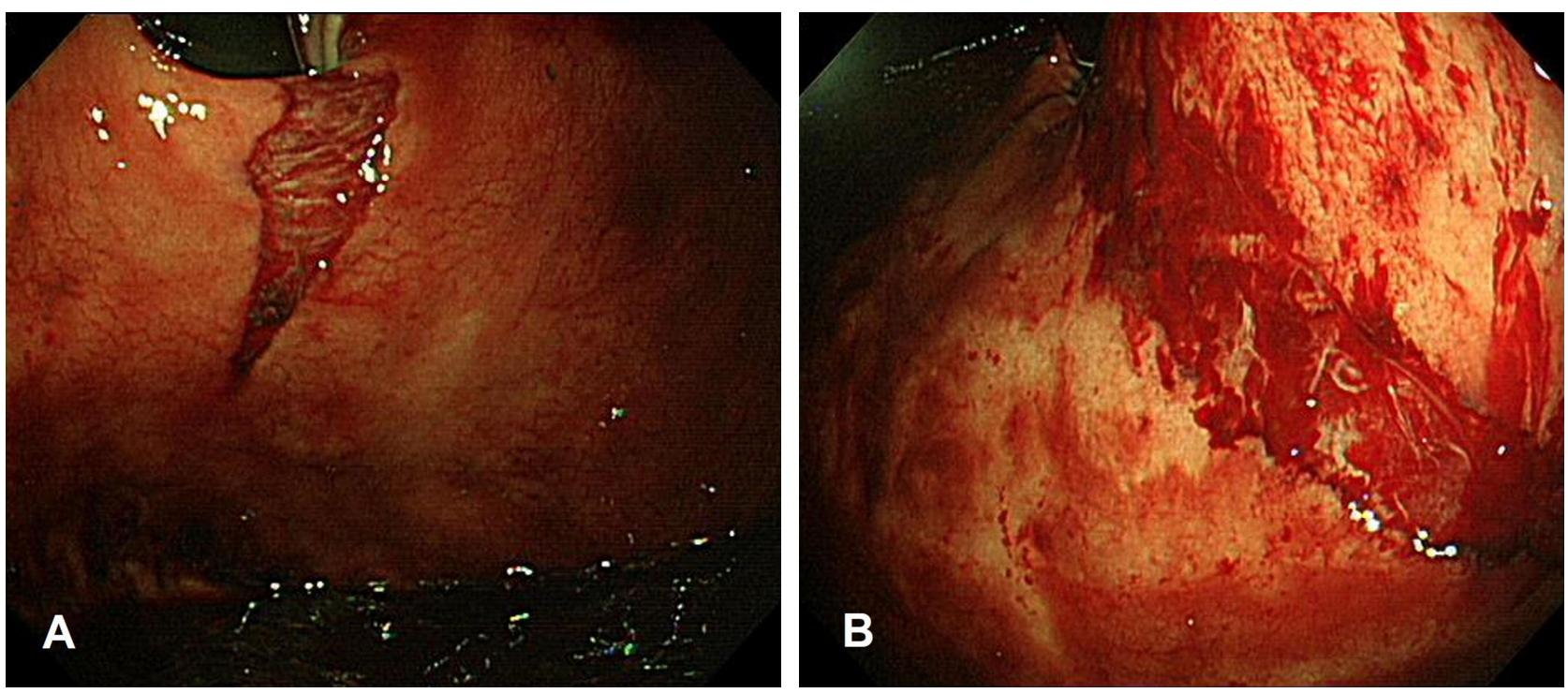

Fig. 2. Stomach endoscopy showing multiple mucosal lacerations toward (A) fundus (approximately $2 \mathrm{~cm}$ long) and (B) lesser curvature (approximately $5 \mathrm{~cm}$ ) from the esophagogastric junction

thickness laceration of stomach is commonly observed on the lesser curvature owing to the impact of the force compressed, probably an empty stomach against the vertebral column (3). In such cases, although abdominal CT reveals negative findings (like in this case), endoscopic examination should be performed for diagnosing suspected gastrointestinal injury, particularly when accompanied with symptoms and signs, such as hematochezia or melena or a suspicious radiological finding. Partial thickness injury of the stomach may be conservatively treated if the intravascular volume is retrieved with volume resuscitation, even though the 
patient is hemodynamically unstable. Initial unstable hemodynamics of the present patient was stabilized with low-dose dopamine and massive transfusion. The transfusion requirement and hematochezia definitely diminished in $41 \mathrm{~h}$ after craniotomy. Endoscopic cauterization, direct clipping, or epinephrine injection for continuous bleeding of the mucosal injury could be certainly attempted, if necessary.

\section{Conflict of Interest Statement}

No potential conflict of interest relevant to this article was reported.

\section{REFERENCES}

1. Watts DD, Fakhry SM. Incidence of hollow viscus injury in blunt trauma: an analysis of 275,557 trauma admission from the east multi-institutional trial. J Trauma. 2003;54: 289-94.

2. Moore EE, Jurkovich GJ, Knudson MM, Cogbill TH, Malangoni MA, Champion HR, et al. Organ injury scaling. VI: Extrahepatic biliary, esophagus, stomach, vulva, vagina, uterus (nonpregnant), uterus (pregnant), fallopian tube, and ovary, J Trauma. 1995;39(6):1069-70.

3. Shinkawa H, Yasuhara H, Naka S, Morikane K, Furuya Y, Niwa $\mathrm{H}$, et al. Characteristic features of abdominal organ injuries associated with gastric rupture in blunt abdominal trauma. Am J Surg. 2004;187(3):394-7. 